\title{
PELAYANAN PARKIR DI RUMAH SAKIT ARIFIN NU'MANG KECAMATAN PANCA RIJANG KABUPATEN SIDENRENG RAPPANG
}

\author{
1) Gustiar Latif, ${ }^{2)}$ Erfina, ${ }^{3)}$ Kamaruddin Sellang \\ Fakultas IImu Sosial dan IImu Politik, Universitas Muhammadiyah Rappang \\ gustiarlatief@gmail.com
}

\begin{abstract}
Abstrak
Penulisan ini bertujuan untuk mengetahui pelayanan parkir di Rumah Sakit Arifin Nu'mang Kecamatan Panca Rijang Kabupaten Sidenreng Rappang, dan untuk mengetahuiFaktor-faktor yang memengaruhi pelayanan parkir di Rumah Sakit Arifin Nu'mang Kecamatan Panca Rijang Kabupaten Sidenreng Rappang. Populasi penulisan ini sebanyak 876pengunjung, sedangkan sampel berjumlah 90 pengunjung. Teknik pengumpulan data yang dilakukan dalam penulisanini adalah menggunakan teknikobservasi,wawancara,studi pustakadankuesioner. Data yang terkumpul kemudian dianalisis dengan menggunakan tabel frekuensi dan persentase.Hasil penulisan ini menunjukkan bahwa pelayanan parkir di Rumah Sakit Arifin Nu'mang Kecamatan Panca Rijang Kabupaten Sidenreng Rappang dengan persentase 68,6 \% dengan kategori baik, sedangkan Faktor-faktor yang memengaruhi pelayanan parkir di Rumah Sakit Arifin Nu'mang Kecamatan Panca Rijang Kabupaten Sidenreng Rappang dengan persentase $69,5 \%$ dengan kategori baik.
\end{abstract}

Kata Kunci: Pelayanan Parkir

\begin{abstract}
This writing aims to determine the parking services at Arifin Nu'mang Hospital, Panca Rijang District, Sidenreng Rappang Regency, and to determine the factors that affect parking services at Arifin Nu'mang Hospital, Panca Rijang District, Sidenreng Rappang Regency. The population of this writing is 876 visitors, while the sample is 90 visitors. Data collection techniques used in this writing are using observation techniques, interviews, literature study and questionnaires. The collected data were then analyzed using frequency and percentage tables. The results of this paper indicate that the parking service at Arifin Nu'mang Hospital, Panca Rijang District, Sidenreng Rappang Regency with a percentage of $68.6 \%$ is in good category, while the factors that affect parking services at Arifin Nu'mang Hospital, Panca Rijang District, Sidenreng Regency Rappang with a percentage of $69.5 \%$ with a good category.
\end{abstract}

Keywords: Parking Service

PRAJA | Volume 7 | Nomor 2 | Edisi Juni 2019 


\section{A. PENDAHULUAN}

Undang-Undang Nomor 23 Tahun 2014 tentang pemerintah Daerah disebutkan sebagai bahwa pemerintah mempunyai kewenangan, tanggungjawab, dan menentukan standar pelayanan minimal,hal ini menjadi tuntutan pada kinerja penyelenggaraan pelayanan masyarakat yang profesional telah menjadi bagian dari tugas pemerintah pusat maupun daerah, kita ketahui semua bahwa orintasi utama kelembagaan pemerintah dalam pelayanan masyarakat. Pelayanan akan terbentuk sebab adanya prose dari sipemberi layanan serta pihak yang menyediakan layanan kepada pihak yang dilayani, sehingga hal tersebut akan terjadi dari seseorang Oleh sebab itu pemberian pelayanan publik oleh aparatur pemerintah kepada masyarakat merupakan perwujudan dan fungsi aparatur negara sebagai pelayan masyarakat.

Pelayanan meruypakan suart respon dalam pemenuhan kebutuhan dimana akan terpenuhi kalau pengguna jasa mendapatkan apa yang dia inginkan, Tidak diperbolehkan dalam hal melayani dirnya tetapi dalam hal melayani seluruh masyarakat, disamping itu perlua adanya penciptaan kondisi yang dapat memungkinkan masyarakat dalam pengembangan kemampuan dalam hal kreativitas untuk pencapaian tujuan.

Pemerintahan yang baik yakni dengan terciptanya pemerintah yang efisien, efektif, transparan, akuntabel dan responsip secara berkesinambungan agar dapat menjadi dambaan bagi lingkup pemerintahana di Daerahnya itu sendiri.. Pemerintahan yang baik sepertia apa yang telah dipaparkan diatas alat sebagai ppelaksanaan seluruh pelayanan publik yang ada di daerah serta alat bagi warga masyarakat agar dapat berperan secara aktif untu penentuan arah dengan peluang serta tantangan yang akan dihadapi dalam mendukung kepentingan pembangunan yang ada di daerah.

Peraturan Daerah (PERDA) Kabupaten Sidenreng Rappang Nomor 1 Tahun 2016 tentang Retribusi Tempat Khusus Parkir, berkembangnya pembangunan gedung di kotakota besar di Indonesia, maka lahan parkir merupakan suatu hal yang penting. Hal ini disebabkan oleh banyaknya pengguna kendaraan pribadi seperti mobil dan motor, oleh sebab itu, pengelolaan parkir harus terus ditingkatkan agar pelayanan parkir dapat lebih maksimal lagi, dalam melakukan peningkatan pelayanan parkir perlu adanya evaluasi dari sistem yang sudah berjalan serta saran untuk meningkatkan pelayanan parkir, dari evaluasi dan saran tersebut dapat dibuat perbaikan sistem parkir yang diharapkan dapat memberikan kenyamaanan saat melakukan parkir.

Seluruha bangunan yang ada dalam lingkup rumah sakit dapat digunakan dalam pemenuhan kebutuhan pelayanan kesehatan, pendidikan dan pelatihan, serta penelitian dan pengembangan ilmu pengetahuan dan teknologi kesehatan, disamping itu ada juga pelataran parkir yang cukup.

Rumah Sakit Arifin Nu'mang merupakan salah satu Rumah Sakit yang terletak di Kecamatan Panca Rijang, meningkatnya kesadaran masyarakat dalam hal kesehatan pengunjung rumah sakit dapat meningkat hal tersebut perlu adanya fasilitas yang mendukung diantaranya tempat parkir area yang cukup memadai, serta perlu diperhatikan keberadaan pusat kegiatan seminimal mungkin dapt membuat gangguansedikit mungkin yang ada disekitarnya. Perancangan fasilitas parkir terszebut dipilih dengan melihat lahan yang memadai serta dalam mengatur parkiran yang perlu adanya pertimbangan dalam hal jaminan keamanan, nyaman, efesiensi, serta lancar bagi pengguan parkir.

Parkiran yang ada dalam rumah sakit sangat mempengaruhi kenyamanan pengunjung, serta area parikir yang cukup memadai akan lebih mudah pelayanan parkir setiap pengunjun, tetapi bila tidak memperhatikan fasilitas pengunjung maka dapat menimbulkan suatu dampak yang kurang baik terhadap lalu lintas dilokasi area lingkungan rumah sakit itu..

Runah sakit meruppakan pelayanan publik atau kegiatan yang banyak dikunjungi sebab ingin berobat dan keadaan kondisi kesehatan masyarakat. Kebutuhan akan kesehatan tentu dapat membawa dampak dalam peningkatan parkir di rumah sakit.

Sebagian besar karyawan dan pengunjung Rumah Sakit Arifin Nu'mangyang menggunakan kendaraan roda empat maupun dua dapat menampung kendaraan itu perlu disediakan tempat parkir yang cukup, pegawai dan pengunjung akan merasa tenang serta aman 
dalam melakukan kegiatanya. Jumlah pasien pada setiap tahunya meningkat dilihat dari pertumbuhan penduduk akan membawa konsekuensi tambahan area parkir diperlukan keberadaan bangunan dapat mempengaruhi pengujung rumah sakit yang datang membesuk.

Berdasarkan pengamatan penulis pada minggu kedua Desember 2019 di Rumah Sakit Arifin Nu'mang Kecamatan Panca Rijang Kabupaten Sidenreng Rappang ditemukan masalah yaitu, adanya pengunjung yang meratap/mengaduh atas pelayanan parkir yang kurang baik contoh pengelolaan parkir kendaraan di Rumah Sakit Arifin Nu'mang Kecamatan Panca Rijang Kabupaten Sidenreng Rappang masih ilegal, masalahnya pengelolaan pelayanan parkir belum melibatkan Dinas Perhubungan berwenang menangani perparkiran dan tidak memiliki karcis. Data tersebut di atas diperoleh melalui wawancara dengan salah satu pengunjung bernama Sri Wahyuni.

Berdasarkan latar belakang di atas penulis mengajukan judul penelitian Pelayanan Parkir di Rumah Sakit Arifin Nu'mang Kecamatan Pancarijang Kabupaten Sidenreng Rappang dengan tujuan Untuk mengetahui pelayanan parkir di Rumah Sakit Arifin Nu'mang Kecamatan Panca Rijang Kabupaten Sidenreng Rappang dan Untuk mengetahui faktor-faktor yang memengaruhi pelayanan parkir di Rumah Sakit Arifin Nu'mang Kecamatan Panca Rijang Kabupaten Sidenreng Rappang.

Moenir (2000:26) Pelayanan publik merupakan seseorang atau kelompok orang dengan memiliki landasan material melalui sistem atau prosedur dengan metode melalui kepentingan orang sesuai dengan hak dan kebutuhanya.Kotler dalam Sampara (2003: 8) mengemukakan pelayanan yaitu kegiatan yang menguntungkan suatu kumpulan atau kesatuan dan menawarkankepuasan, meski hasil tidak memiliki keterikatan dalam suatu produk secara fisik Lebih lanjut dijelaskan bahwa dalam pemberian layanan kegiatan berlangsung melalui suatu itraksi langsung dengan seseorang atau secara mesin secara fisik.

Menurut Fitzsimmons dalam Sinambela dkk, (2014:7), untuk mengetahui kualitas pelayanan yang dirasakan secara nyata oleh masyarakat, ada lima indikator yang dapat digunakan untuk mengetahui kualitas pelayanan parkir tersebut, yaitu: (a) Bukti Langsung , yang meliputi fasilitas fisik, Fasilitas fisik yang dimaksud disini adalah seperti tempat parkir, (b) Daya Tanggap, yaitu keinginan para staf untuk membantu masyarakat dan memberikan pelayanan dengan tanggap. Keinginan itu seperti kemauan aparat birokrasi untuk memberikan informasi-informasi yang terkait dengan waktu pelayanan,(c) Keandalan), yaitu kemampuan memberikan pelayanan dengan segera dan memuaskan. Hal ini dapat dilihat dari kemampuan dan kecakapan aparat birokrasi dalam mengerjakan tugas-tugas yang dibebankan dan menjadi kewajibannya dengan cepat sesuai waktu yang dijanjikannya. (d) Jaminan, yaitu mencakup sifat dapat dipercaya yang dimiliki para staf (e) Empati, yaitu meliputi kemudahan dalam melakukan hubungan komunikasi yang baik dan memahami kebutuhan para pelanggan.

Faktor yang mendukung pelayanan parkirmenurut Moenir, (2010: 88) yaitu:

1. Faktor Kesadaran: Suatu proses berpikir melalui metode renungan,pertimbangan dan perbandingan, sehingga menghasilkan keyakinan, ketenangan, ketetapan hati dan keseimbangan dalam jiwanya sebagai pangkal tolak untuk perbuatan dan tindakan yang akan dilakukan kemudian.

2. Faktor Aturan adalah perangkat penting dalam segala tindakan dan perbuatan orang. Makin maju dan majemuk suatu masyarakat makin besar peranan aturan dan dapat dikatakan orang tidak dapat hidup layak dan tenang tanpa aturan.

3. Faktor Organisasi : Organisasi pelayanan pada dasarnya tidak berbeda dengan organisasi pada umumnya tetapi ada sedikit perbedaan dalam penerapannya, karena sasaran pelayanan ditujukan secara khusus kepada manusia yang mempunyai watak dan kehendak multi kompleks.

4. Faktor Pendapatan ialah seluruh penerimaan seseorang sebagai imbalan atas tenaga dan/atau pikiran yang telah dicurahkan untuk orang lain atau badan/organisasi, baik dalam bentuk uang, natura maupun fasilitas, dalam jangka waktu tertentu.

5. Faktor Kemampuan dan Keterampilan Kemampuan berasal dari kata dasar mampu yang dalam hubungan dengan tugas/pekerjaan berarti dapat (kata 
sifat/keadaan) melakukan tugas/pekerjaan sehingga menghasilkan barang atau jasa sesuai dengan yang diharapkan. Kata jadian kemampuan dengan sendirinya juga kata sifat/keadaan yang ditujuka pada sifat atau keadaan seseorang yang dapat melaksanakan tugas/pekerjaan atas dasar ketentuan-ketentuan yang ada.

6. Faktor Sarana Pelayanan : Sarana pelayanan yang dimaksud disisni ialah segala jenis peralatan, perlengkapan kerja dan fasilitas lain yang berfungsi sebagai alat utama/pembantu dalam pelaksanaan pekerjaan, dan juga berfungsi sosial dalam rangka kepentingan orang-orang yang sedang berhungan dengan organisasi kerja itu.

\section{B. METODE PENELITIAN}

Lokasi pada penelitian ini yaitu di Rumah Sakit Arifin Nu'mang Kecamatan Panca Rijang Kabupaten Sidenreng Rappang.Penelitian ini menggunakan tipe penelitian deskriptif kuantitatif, dengan metode inii diharapkan dapat memberikan gambaran secara cermat, jelas, dan objektif mengenai masalah yang sedang diteliti. Sedangkan jenis penelitian yang dilakukan adalah survei dimana kegiatan penelitian menggunakan kuesioner dan wawancara sebagai instrumen dalam pengumpulan data di lapangan. Dalam penelitian terdapat satu variabel yakni implementasi.

Populasi pada penelitian ini adalah pengunjung di Rumah Sakit Arifin Nu'mang Kecamatan Panca Rijang Kecamatan Panca Rijang Kabupaten Sidenreng Rappang sebanyak 876 selama dua bulan, pada teknik acak ini dilakukan penentuan jumlah sampel minimum dapat mewakili populasi dengan menggunakan Rumus Slovin dengan tingkat kesalahan $10 \%$, jadi jumlah sampel dalam hal ini sebanyak 90 orang pengunjung.

\section{HASIL DAN PEMBAHASAN}

Rumah Sakit Arifin Nu'mang Kecamatan Panca Rijang Kabupaten Sidenreng Rappang adalah salah satu Rumah Sakit milik Pemerintah Daerah Sidenreng Rappang yang merupakan Rumah Sakit yang tertua di Kabupaten Sidenreng Rappang yang dibangun pada tahun 1938 diatas tanah seluas $1 \mathrm{Ha}$, yang terletak di
Kota Rappang Tidak lebih $10 \mathrm{Km}$ dari IbuKota Kabupaten.Letak geografis yang strategis dan mudah dijangkau dibandingkan dengan Rumah Sakit lain yang berada di IbuKota Kabupaten adalah merupakan satu pelung besar untuk terpilih sebagai Rumah Sakit rujukan dari Puskesmas, Rumah Sakit atau pelayanan kesehatan lainnya baik dalam Wilayah Kabupaten Sidenreng Rappang maupun yang berasal dari daerah Kabupaten lainnya.

Sejalan dengan perubahan dan tata ruang Kota yang ada, maka fungsi Rumah Sakit Umum Rappang mengalami perubahan menjadi Rumah Sakit Besalin Daerah Rappang sesuai Kebutuhan Bupati Sidenreng Rappang Nomor: KPTS. 007/VIII/1995, tentang Pembentukan Organisasi Rumah Sakit Bersalin Daerah Rappang.Pada tahun 2002 terjadi perubahan kelembagaan sesuai peraturan Daerah Nomor : 05 Tahun 2002, tanggal 16 Februari 2002, tentang pembentukan dan Susunan Organisasi Rumah Sakit Umum Arifin Nu'mang, maka Rumah Sakit ini berubah dari Rumah Sakit Sayang Ibu dan Anak menjadi Rumah Sakit Umum Arifin Nu'mang Kabupaten Sidenreng Rappang.Selanjutnya pada tahun 2004 berdasarkan Surat Keputusan Bupati Sidenreng Rappang Nomor : 29 Tahun 2004 tentang pembentukan dan Susunan Organisai Rumah Sakit Umum Daerah Arifin Nu'mang, tanggal 28 Mei 2004, maka Rumah Sakit Umum Daerah Arifin Nu'mang Kabupaten Sidenreng Rappang.

1. Tempat parkir di Rumah Sakit Arifin Nu'mang Kecamatan Panca Rijang Kabupaten Sidenreng.

Tempat parkir di Rumah Sakit Arifin Nu'mang Kecamatan Panca Rijang Kabupaten Sidenreng Rappang adalah 8 orang (8,89\%) responden menjawab Sangat Baik, 44 orang $(48,89 \%)$ responden menjawab Baik, 23 orang $(25,56 \%)$ responden menjawab Kurang Baik dan 15 orang $(16,67 \%)$ responden menjawab Tidak Baik, serta tidak ada responden yang menjawab Sangat Tidak Baik.

2. informasi mengenai parkir yang dibutuhkan masyarakat di Rumah Sakit Arifin Nu'mang Kecamatan Panca Rijang Kabupaten Sidenreng Rappang.

Informasi mengenai parkir yang dibutuhkan masyarakat di Rumah Sakit Arifin Nu'mang Kecamatan Panca Rijang Kabupaten Sidenreng Rappang adalah 9 orang (10\%) 
responden menjawab Sangat Baik, 43 orang $(47,78 \%)$ responden menjawab Baik, 18 orang $(20 \%)$ responden menjawab Kurang Baik dan 20 orang $(22,22 \%)$ responden menjawab Tidak Baik, serta tidak ada responden yang menjawab Sangat Tidak Baik.

3. petugas parkir di Rumah Sakit Arifin Nu'mang Kecamatan Panca Rijang Kabupaten Sidenreng Rappang.

Petugas parkir di Rumah Sakit Arifin Nu'mang Kecamatan Panca Rijang Kabupaten Sidenreng Rappang cepat dalam melayani masyarakat adalah 4 orang $(4,44 \%)$ responden menjawab Sangat Baik, 42 orang $(46,67 \%)$ responden menjawab Baik, 15 orang (16,67\%) responden menjawab Kurang Baik 29 orang $(32,22 \%)$, responden menjawab Tidak Baik, dan tidak ada responden yang menjawab Sangat Tidak Baik.

4. Tingkat perhatian yang dimiliki petugas parkir dalam memberikan pelayanan kepada masyarakat di Rumah Sakit Arifin Nu'mang Kecamatan Panca Rijang Kabupaten Sidenreng Rappang.

Perhatian yang dimiliki petugas parkir dalam memberikan pelayanan kepada masyarakat di Rumah Sakit Arifin Nu'mang Kecamatan Panca Rijang Kabupaten Sidenreng Rappang adalah 6 orang $(6,67 \%)$ responden menjawab Sangat Baik, 44 orang $(48,89 \%)$ responden menjawab Baik, 22 orang $(24,44 \%)$ responden menjawab Kurang Baik 18 orang (20\%), responden menjawab Tidak Baik, dan tidak ada responden yang menjawab Sangat Tidak Baik.

5. komunikasi antara petugas parkir dengan masyarakat di Rumah Sakit Arifin Nu'mang Kecamatan Panca Rijang Kabupaten Sidenreng Rappang.

Hubungan komunikasi antara petugas parkir dengan masyarakat di Rumah Sakit Arifin Nu'mang Kecamatan Panca Rijang Kabupaten Sidenreng Rappang adalah 8 orang $(8,89 \%)$ menjawab Sangat Baik, 47 orang $(52,22 \%)$ menjawab Baik, 20 orang (22,22 \%) menjawab Kurang Baik dan 15 orang (16,67\%) menjawab Tidak Baik, serta tidak ada yang menjawab Sangat Tidak Baik.

6. Rekapitulasi tanggapan responden tentang indikator pelayanan parkir dengan masyarakat di Rumah Sakit Arifin Nu'mang
Kecamatan Panca Rijang Kabupaten Sidenreng Rappang.

Rekapitulasi indikator pelayanan parkir dengan masyarakat di Rumah Sakit Arifin Nu'mang Kecamatan Panca Rijang Kabupaten Sidenreng Rappang dengan capaian $68,6 \%$ yang berdasarkan berbagai pertanyaan sesuai dengan indikator di atas termasuk dalam kategori baik.

Selanjutnya, faktor yang mempengaruhi pelayanan parkir yang ada di rumah sakit Arifin Nu'mang.

1. tanggungjawab petugas dalam memberikan pelayanan parkir di Rumah Sakit Arifin Nu'mang Kecamatan Panca Rijang Kabupaten Sidenreng Rappang.

Tanggungjawab petugas dalam memberikan pelayanan parkir di Rumah Sakit Arifin Nu'mang Kecamatan Panca Rijang Kabupaten Sidenreng Rappang adalah 8 orang $(8,89 \%)$ menjawab Sangat Baik, 47 orang $(52,22 \%)$ menjawab Baik, 20 orang $(22,22 \%)$ menjawab Kurang Baik dan 15 orang (16,67\%) menjawab Tidak Baik, serta tidak ada yang menjawab Sangat Tidak Baik.

2. Aturan parkir yang berlakudi Rumah Sakit Arifin Nu'mang Kecamatan Panca Rijang.

Aturan parkir yang berlakudi Rumah Sakit Arifin Nu'mang Kecamatan Panca Rijang adalah 4 orang $(4,44 \%)$ responden menjawab Sangat Baik, 42 orang $(46,67 \%)$ responden menjawab Baik, 15 orang $(16,67 \%)$ responden menjawab Kurang Baik 29 orang $(32,22 \%)$, responden menjawab Tidak Baik, dan tidak ada responden yang menjawab Sangat Tidak Baik.

3. pembagian tugas dalam pelayanan parkir di Rumah Sakit Arifin Nu'mang Kecamatan Panca Rijang Kabupaten Sidenreng Rappang.

Pembagian tugas dalam pelayanan parkir di Rumah Sakit Arifin Nu'mang Kecamatan Panca Rijang Kabupaten Sidenreng Rappang adalah 8 orang $(8,89 \%)$ responden menjawab Sangat Baik, 44 orang $(48,89 \%)$ responden menjawab Baik, 23 orang $(25,56 \%)$ responden menjawab Kurang Baik dan 15 orang (16,67\%) responden menjawab Tidak Baik, serta tidak ada responden yang menjawab Sangat Tidak Baik.

4. biaya parkir yang diberikan petugas dalam memberikan pelayanan parkir kepada masyarakat di Rumah Sakit Arifin Nu'mang 
Kecamatan Panca Rijang Kabupaten Sidenreng Rappang.

Biaya parkir yang diberikan petugas dalam memberikan pelayanan parkir kepada masyarakat di Rumah Sakit Arifin Nu'mang Kecamatan Panca Rijang Kabupaten Sidenreng Rappang adalah 8 orang $(8,89 \%)$ menjawab Sangat Baik, 47 orang $(52,22 \%)$ menjawab Baik, 20 orang $(22,22 \%)$ menjawab Kurang Baik dan 15 orang $(16,67 \%)$ menjawab Tidak Baik, serta tidak ada yang menjawab Sangat Tidak Baik.

5. keterampilan petugas parkir dalam memberikan pelayanan di Rumah Sakit Arifin Nu'mang Kecamatan Panca Rijang Kabupaten Sidenreng Rappang.

Keterampilan petugas parkir dalam memberikan pelayanan di Rumah Sakit Arifin Nu'mang Kecamatan Panca Rijang Kabupaten Sidenreng Rappang adalah 9 orang (10\%) responden menjawab Sangat Baik, 43 orang $(47,78 \%)$ responden menjawab Baik, 18 orang (20\%) responden menjawab Kurang Baik dan 20 orang $(22,22 \%)$ responden menjawab Tidak Baik, serta tidak ada responden yang menjawab Sangat Tidak Baik.

6. Rehabilitasi peralatan yang dipakai dalam pelayanan parkir di Rumah Sakit Arifin Nu'mang Kecamatan Panca Rijang Kabupaten Sidenreng Rappang.

Peralatan yang dipakai dalam pelayanan parkir di Rumah Sakit Arifin Nu'mang Kecamatan Panca Rijang Kabupaten Sidenreng Rappang adalah 6 orang $(6,67 \%)$ responden menjawab Sangat Baik, 44 orang $(48,89 \%)$ responden menjawab Baik, 22 orang $(24,44 \%)$ responden menjawab Kurang Baik 18 orang (20\%), responden menjawab Tidak Baik, dan tidak ada responden yang menjawab Sangat Tidak Baik.

7. Faktor-faktor yang memengaruhi pelayanan parkir di Rumah Sakit Arifin Nu'mang Kecamatan Panca Rijang Kabupaten Sidenreng Rappang.

Rekapitulasi faktor-faktor yang memengaruhi pelayanan parkir di Rumah Sakit Arifin Nu'mang Kecamatan Panca Rijang Kabupaten Sidenreng Rappang terdiri dari faktor kesadaran, faktor aturan, faktor organisasi, faktor pendapatan, faktor kemampuan keterampilan, dan faktor sarana pelayanan dengan capaian $69,5 \%$ termasuk dalam kategori baik.

\section{Kesimpulan}

Pada bab terdahulu telah diuraikan mengenai hasil penelitian dan pembahasan maka kesimpulan sebagai berikut :

1. Pelayanan parkir di Rumah Sakit Arifin Nu'mang Kecamatan Panca Rijang Kabupaten Sidenreng Rappangdalam penelitian ini berada pada kategori baik.

2. Faktor-faktor yang memengaruhi pelayanan parkir di Rumah Sakit Arifin Nu'mang Kecamatan Panca Rijang Kabupaten Sidenreng Rappangdalam penelitian ini berada pada kategori baik.

\section{E. Daftar Pustaka}

Ahmad, Jamaluddin. 2015. Metode Penelitian Administrasi Publik Teori dan Aplikasinya. Gama Media. Yogyakarta.

A.S Moenir, 2000. Manajemen Pelayanan Umum Di Indonesia. Bumi Aksara. Jakarta.

Boediono, B. 2006. Pelayanan Prima.Yayasan Kuala Indonesia. Jakarta.

Hamzah B. Uno, 2014, Teori Kinerja dan Pengukurannya. Bumi Aksara. Jakarta

Hardiyansyah. 2011. Kualitas Pelayanan Publik: Konsep, Dimensi, Indikator, dan Implementasinya. Penerbit Gava Media. Yogyakarta.

Ibarahim. 2008. Teori dan Konsep Pelayanan Publik serta Implementasinya. Mandar. Bandung.

Kamaruddin Sellang. 2016. Administrasi dan Pelayanan Publik. Ombak. Yogyakarta.

Kamus Besar Bahasa Indonesia. Edisi Ketiga. 2005. Departemen Pendidikan dan Kebudayaan. Balai Pustaka. Jakarta.

Kurniawan dan Najib. 2005. Transformasi Pelayanan Publik. Pembaruan. Yogyakarta. 
Miftah Thoha. 2002 Pelayanan Umum, Raja Grafindo Persada, Jakarta.

Moenir, H.A.S., 2003, Manajemen Pelayanan Umum di Indonesia, Bumi Aksara, Jakarta.

Moenir, 2007, Manajemen Pelayanan Umum di Indonesia, Bumi Aksara, Jakarta.

Mulyadi dan Setiawan, 2001, Efektivitas Pelayanan Publik, Pratama, Surabaya.

Munir, 2000.Manajemen Pelayanan Umum di Indonesia. Bumi Aksara. Jakarta.

Nasution. 2004. Reformasi Pelayanan Publik. Bumi Aksara. Jakarta.

Nurman, 2015. Strategi Pembangunan Daerah, Rajawali Pers, Pekan Baru.

Sugiyono. 2012. Metode Penelitian Administrasi Dilengkapi dengan Metode R\&D. Alfabeta. Bandung.

Sinambela $d k k$, 2014. Reformasi Pelayanan Publik, Bumi Aksara, Jakarta.

S, Yogi dan M. Ikhsan. 2006. Standar Pelayanan Publik Di Daerah. PKKODLAN.

Waluyo, 2007, Manajemen Publik, Mandar Maju, Bandung.

Zulkifli Zaini. 2014. Mengelola Kualitas Layanan Perbankan. Gramedia Pustaka Utama, Jakarta. 